\title{
Sub-Acute Sclerosing Panencephalitis Presenting as Anti-Depressant Induced Childhood Mania
}

\author{
Bilal Ahmad Bhat*, Shabir Ahmad Dar and Arshad Hussain
}

Department of Psychiatry, Government Medical College, Shrinagar, India

\begin{abstract}
Subacute sclerosing panencephalitis (SSPE) is a rare, predominantly childhood onset neurological illness that probably results from a latent or mutant measles virus infection of neurons with slowly progressive disease resulting in severe neurological deficit and death. In literature there have been reports of pure psychiatric symptoms as presenting complaints in patients with SSPE. We hereby describe a case of 8 year old boy, who presented with depression and developed symptoms of mania on antidepressant but eventually developed the typical symptoms of SSPE highlighting the importance of keeping in mind the differential diagnosis of organic causes for childhood depression and mania.
\end{abstract}

Keywords: Subacute sclerosing; Panencephalitis; Psychiatric symptoms

\section{Introduction}

Sub-acute sclerosing panencephalitis (SSPE) is a rare progressive, invariably fatal long-term complication of measles infection. The average onset (latency) period from initial measles infection to development of SSPE symptoms is usually 4 and 10 years [1]. Although personality and behavioral changes are common early in the course of SSPE but pure psychiatric disorder as an early manifestation of this fatal neurological disorder has been rare $[2,3]$. We hereby describe a case of 8 year old boy, who presented with depression and developed symptoms of mania on antidepressant but eventually developed the typical symptoms of SSPE highlighting the importance of keeping in mind the differential diagnosis of organic causes for childhood depression and mania [3-10]. Our case is unique in that it was a rare case of antidepressant induced mania eventually turning out to be a case of SSPE. Institutional ethical committee approved the publication of this case.

\section{Case Report}

An eight year old boy was brought by his father with complaints of change in his behavior in the form of excessive talking, overfamiliar behavior, decreased sleep, spitting on others, excessive playing and hyperactivity since one week. There was no significant medical history or family history. On mental status examination, he was hyperactive in the examination room and appeared cheerful, had spontaneous speech, had an elated mood and was overfamiliar. He was oriented to time, place and person and his memory was intact. His general physical and neurological examinations were normal except for sagging of his left shoulder while walking. The boy had been apparently well three weeks back when he started with decreased interaction with his family members and friends. He would remain alone, would not play with his younger brother and other boys in the community and would remain confined to his room. He also refused to go to school. Occasionally he would cry for no reasons. He was taken to a psychiatrist who diagnosed him as a case of childhood onset depression and put him on fluoxetine $10 \mathrm{mg}$. After taking fluoxetine he started improving in few days but after two weeks, on fluoxetine, he started with above symptoms (excessive talking, overfamiliar behavior, decreased sleep, spitting on others, excessive playing and hyperactivity) of mania. One week after the development of mania symptoms he was brought to us. There was no past and family history of mood disorder. Routine hematological investigations and ECG were normal. Attention-deficit/hyperactivity disorders (ADHD) were ruled out as the symptoms were not pervasive in this case and were present since last week only. We diagnosed him as antidepressant induced mania and stopped fluoxetine and started divalproex sodium $250 \mathrm{mg}$ twice daily. After two weeks on follow-up, there was not much improvement with an additional complaint of sudden throwing of items from his hand. On examination there were myoclonic jerks and we sought a neurological consultation who advised an EEG, MRI brain and follow-up in neurology OPD. On our followup at six weeks, there was exacerbation in his symptoms and in the meantime he had been worked up by neurologist. Magnetic resonance imaging was not done because of financial constraints for the patient. There were bilaterally symmetrical periodic complexes on EEG.

\section{Discussion}

His cerebrospinal fluid (CSF) was clear, a-cellular, with normal pressure, protein and sugar levels but with high titers of anti-measles IgG antibodies. A diagnosis of SSPE had been made. The patient on follow-up over next 6-7 months deteriorated with increase in frequency of myoclonic jerks, progressive decline in comprehension, urinary and fecal incontinence could not take care of him and had to be assisted by family members for his daily routine. His gait became progressively unsteady with frequent falls and ultimately he died.

\section{Conclusion}

Neurologists, pediatricians and psychiatrists should have a high index of suspicion in children presenting with depression or mania especially from areas with high prevalence of SSPE for early diagnosis and should include SSPE in the differential diagnosis of childhood depression and mania.

*Corresponding author: Bilal Ahmad Bhat, Department of Psychiatry Government Medical College, Shrinagar, Jammu and Kashmir, India, Tel: 917006351640/919596272573; Fax: 9086930515; E-mail: bilalahmadbhat69@ gmail.com

Received: April 30, 2018; Accepted: June 14, 2018; Published: June 21, 2018

Citation: Bhat BA, Dar SA, Hussain A (2018) Sub-Acute Sclerosing Panencephalitis Presenting as Anti-Depressant Induced Childhood Mania. J Psychiatry 21: 452. doi:10.4172/2378-5756.1000452

Copyright: $\odot 2018$ Bhat BA, et al. This is an open-access article distributed unde the terms of the Creative Commons Attribution License, which permits unrestricted use, distribution, and reproduction in any medium, provided the original author and source are credited. 
Citation: Bhat BA, Dar SA, Hussain A (2018) Sub-Acute Sclerosing Panencephalitis Presenting as Anti-Depressant Induced Childhood Mania. J Psychiatry 21: 452. doi:10.4172/2378-5756.1000452

Page 2 of 2

\section{Reference}

1. Campbell H, Andrews N, Brown KE, Miller E (2007) Review of the effect of measles vaccination on the epidemiology of SSPE. Int J Epidomol 36: 13341348.

2. Garg RK (2008) Subacute sclerosing panencephalitis. J Neurology 255: 18611871.

3. Gutierrez J, Issacson RS, KoppelBS (2010) Subacute sclerosingpanencephalitis: An update. Develop Med Child Neurolo 52: 901-907.

4. Reddy B, Das S, Guruprasad S (2017) Primary psychiatric manifestations of subacute sclerosing panencephalitis: A case report and the literature review. Psychosomatics.

5. Forrest G, Stores G (1996) Subacute sclerosing panencephalitis presenting with psychosis and possible sexual abuse. Eur Child Adolesc Psychiatry 5: 110-13.
6. Kartal A, Kurt AN, Gürkaş E, Aydin K, Serdaroğlu A (2014) Subacute sclerosing panencephalitis presenting as schizophrenia with an alpha coma pattern in a child. J Child Neurology 29: NP111-3.

7. Jahnel M (2003) Paranoid-Hallucinatory psychosis as primary manifestation of subacutesclerosingpanencephalitis (SSPE) in a 19 years-old man. Psychiatr Prax 30: 70-72.

8. Aggarwal A, Khandelwal A, Jain M, Jiloha RC (2011) Subacute sclerosing panencephalitis presenting as mania. Annals Ind Academy Neurolo 14: 120121.

9. Kayal M, Varghese ST, Singh Balhara YP (2006) Psychiatric manifestation of SSPE. J Neuropsychiatry Clin Neurosci 18: 560.

10. Datta SS, Jacob R, Kumar S, Jeyabalan S (2006) A case of subacute sclerosing panencephalitis presenting as depression. Acta Neuropsychiatr 18: 55-57. 